\title{
Affecting patients with work-related problems by educational training of their GPs: a cost-effectiveness study
}

\author{
Cornelis de Kock ${ }^{1 * \dagger} \mathbb{D}$, Cindy Noben ${ }^{2,9 \dagger}$, Antoine Lagro-Janssen ${ }^{2}$, Peter Lucassen ${ }^{3}$, André Knottnerus ${ }^{4}$, \\ Angelique de Rijk ${ }^{5}$, Frans Nijhuis ${ }^{6^{\wedge}}$, Romy Steenbeek ${ }^{7}$ and Silvia Evers ${ }^{2,8}$
}

\begin{abstract}
Background: Assessing the cost effectiveness of training aimed at increasing general practitioners' (GP) work awareness and patients' work-related self-efficacy and quality of life.

Methods: A cluster randomized controlled trial in twenty-six GP practices in the southeast of the Netherlands with 32 participating GPs. GPs working in an intervention group practice received training and GPs working in a control group practice delivered usual care. The training intervention consisted of lectures and workshops aimed at increasing GPs' work awareness and more proactive counseling for patients with work-related problems (WRP). Subjects were working age patients with paid work for at least $12 \mathrm{~h}$ per week, who visited one of the participating GPs during the study period. As outcome measures we used the Return to Work Self Efficacy scale to assess patients' work-related self-efficacy and the Euroquol to assess quality of life. We also measured health care costs and productivity costs. With a 4-item questionnaire we asked patients to assess their GPs' work awareness. Data were collected at baseline, after 6 and 12 months.
\end{abstract}

Results: Data of 280 patients could be analyzed. The patient related outcomes did not improve after GP training. The change in GP work awareness and the overall mean cost difference (of $€ 770$ ) in favor of the intervention group were not significant.

Conclusions: The training intervention presented in this paper was not cost-effective. Training which is further personalized and targeted at high risk groups with respect to WRP, is more likely to be cost effective.

Keywords: Health economics, Occupational/environmental medicine, Primary care, Randomized controlled trial, Rehabilitation/disabilities

\section{Background}

Although most health professionals acknowledge the importance of their patient's work, occupation and the ability to work often are not discussed during consultations. Even general practitioners (GPs), who are trained to deliver patient-centred care, accounting for the background and context of their patients, do not always pay attention to work-related health issues [1-3]. Nonetheless,

\footnotetext{
* Correspondence: Kees.deKock@radboudumc.nl

${ }^{\dagger}$ Cornelis de Kock and Cindy Noben contributed equally to this work.

Deceased

${ }^{1}$ Department of Primary and Community Care, Gender and Women's Health, Radboud University Nijmegen Medical Center, PO Box 9101, 6500, HB, Nijmegen, The Netherlands

Full list of author information is available at the end of the article
}

a more active role of primary care providers with respect to their patients' working context is valuable because of the beneficial relation between work and health. Previous studies have demonstrated this relation in both care- and cure settings [4-6]. In order to reduce practice variation, The Health Council of the Netherlands published a set of guidelines about the management of diseases which frequently lead to long term sickness absence [7]. And in the UK the Department of Work and Pensions (DWP) in 2010, replaced the sickness certificate by the "Fit Note" and more recently investigated the effect of telephonic support $[8,9]$. When the Fit Note was introduced, the National Education Programme offered workshops developed by the Royal College of GPs which were attended by

(c) The Author(s). 2019 Open Access This article is distributed under the terms of the Creative Commons Attribution 4.0 International License (http://creativecommons.org/licenses/by/4.0/), which permits unrestricted use, distribution, and reproduction in any medium, provided you give appropriate credit to the original author(s) and the source, provide a link to the Creative Commons license, and indicate if changes were made. The Creative Commons Public Domain Dedication waiver (http://creativecommons.org/publicdomain/zero/1.0/) applies to the data made available in this article, unless otherwise stated. 
2865 GPs. This programme resulted in an increased confidence managing consultations regarding work and health among the GPs [10]. When using the Fit Note, GPs can specify the way in which a patient's work should be modified to make return to work possible [9]. Other strategies aimed to improve the collaboration between professionals working in curative health settings and those working in occupational health settings [11-13]. So far these strategies have had at best limited success [14, 15]. Moreover, if collaboration was achieved, it did not necessarily improve the outcomes with respect to return to work [16]. Studies using multifactorial analyses to find out which GP factors influence sick leave showed contradictory results and on the whole did not indicate GPs are an important factor [17-20].

For most GPs sickness certification or giving advice about work is not amongst their most preferred activities $[21,22]$. This has been explained by the complexity of the task and by the fact that GPs tend to prioritise the interest of and relation with their patients, over those of other stakeholders [23, 24]. For Dutch GPs, an extra reason may be the fact that they, unlike their colleagues in other countries, do not have a formal role in sickness certification or in work rehabilitation [5, 25]. Still, GPs who want to deliver patient-centred care should structurally and proactively discuss paid work as one of the important context factors [26-28]. This is considered to be beneficial for several reasons: it can lead to better analyses of health problems and better tailoring of treatment strategies; GPs possibly recognise workrelated problems (WRP) earlier and thus may prevent (long term) sick leave; the collaboration between primary care and other professionals involved in workers' health may benefit from sharing a common agenda [2, 11]. In other studies it was demonstrated that training GPs can increase their patient centredness and help them to recognise and address difficult subjects like family violence $[29,30]$.

Therefore, we developed an educational GP training program aimed at making GPs more attentive to their patients' work context and improve their management of WRP [31]. We performed this study to determine whether the GP training programme is cost-effective with respect to patient's work-related self-efficacy and quality of life. We will also assess the effect on GPs' work awareness. To assess the influence of potential confounding factors, gender aspects and work-related aspects were studied as well.

\section{Methods}

An educational GP training program was developed to make GPs more attentive to the context of their patients' work. We conducted a cluster randomized controlled trial (RCT) in which GPs were randomized to the intervention group or the control group. GPs working in the same practice were allocated to the same group to prevent contamination. Intervention group GPs received educational training, control group GPs provided usual care. The results with respect to the patient level and GP level outcomes were recently published [32]. This paper reports on the cost-effectiveness of our intervention with respect to work-related self-efficacy and quality of life. Detailed information regarding the methodology of this trial has been published elsewhere [31, 32].

\section{Intervention and usual care}

GPs in the intervention group received accredited 5-h training which was based on the findings of previously conducted focus groups [33]. Seven items were covered in lectures and interactive workshops during the training: (i) the societal relevance of a proactive approach of the connection between work and health by GPs; (ii) reflection by the participants on their 'usual care' for WRP and barriers to provide care for WRP; (iii) legislation regarding work and absenteeism, the role of occupational physicians (OPs) and collaboration between GPs and OPs; (iv) gender aspects of work and WRP; (v) demonstration of good practice for the management of WRP, consisting of an activating approach, scheduling at least one follow-up visit and counselling, for instance about a timely discussion of problems with a supervisor or OP rather than staying home without a plan; (vi) structural registration of work-related data in the electronic medical files including adequate coding according to the International Classification of Primary Care (ICPC); and (vii) information about study logistics and data collection. Three months after the initial training a three hour booster training took place [31]. GPs included in the control group provided care as usual. After the study, GPs in the care as usual group were also offered the educational training as an incentive for adhering to the study protocol [31].

\section{Patient population}

Between February 2012 and January 2013 all patients visiting participating GPs were invited by the receptionist to complete a short questionnaire to check the inclusion criteria. Patients were included if they: (i) were 1863 years of age, (ii) had paid work for at least twelve hours per week, (iii) sufficiently understood the Dutch language and (iv) had given their informed consent. Patients were excluded from the study if more than twelve months had elapsed between completions of two consecutive questionnaires. Furthermore, at least two out of three measures on the Return To Work Self-Efficacy scale (RTW-SE) had to be completed in order to provide a meaningful interpretation for the economic analyses on the impact of the training on patients. 
After informed consent participants received the first questionnaire (see Additional file 1). After at least six months a second questionnaire followed and after at least another six months the final questionnaire had to be completed. Depending on the patient's preferences, paper or online questionnaires were handed out or mailed to them.

\section{Outcome measures}

The main outcome for the cost-effectiveness analysis was work-related self-efficacy measured by the eleven item Return-to-Work Self-Efficacy (RTW-SE) scale. This scale has been validated in sick-listed patients in whom it predicted return to work. It measures the extent to which people feel able to handle the demands of their job using 11 items, which can be rated from ' 1 ' (completely disagree) to ' 6 ' (completely agree) [34]. The total score ranges from 1 to 6 , with higher values indicating better work-related self-efficacy. As we included patients with paid work, rather than patients on sick leave, we called the construct we measured "work-related self-efficacy", rather than "return to work self-efficacy".

The main outcome for the cost-utility analysis was quality adjusted life years (QALY), measured by using the EQ-5D-5 L. This questionnaire measures the patient's health state of 5 dimensions on 5 levels ranging from no problems to extreme problems. The dimensions are mobility, self-care, usual activities, pain/discomfort, and anxiety/depression. The score ranges from 5 to 25 , with higher scores indicating worse functioning. To estimate the utility of health states described by the patients, the EQ-5D-5 L crosswalk value set with the Dutch tariff was used [35]. Higher QALYs indicate more improvement in quality of life.

GP work awareness was measured with the self-developed GP work awareness scale (GWAS). In this 4 item scale, patients are asked whether the GP knows their occupation, discusses a possible relation between their health problem and their work, discusses sick leave, and helps to find solutions for any WRP. Each item can be rated ' 1 ' (agree) or ' 0 ' (not agree) and thus the scale ranges from 0 to 4 .

\section{Cost measures}

Cost data were collected from a societal perspective meaning that all costs and benefits will be captured independently of those who bear the costs or those who receive the benefits [36]. All costs were measured from 2012 onwards (start of handing out the first questionnaires) and therefore adjusted to the index year 2012 using consumer price indices. In the questionnaires we asked how often, over the last 6 months, the participants had taken sick leave, visited different health care professionals, were admitted to hospitals, received informal care, and multiplied these frequencies with the standard costs of sick leave and prices of care. By adding these components we calculated the costs. All costs where categorized and calculated in 4 main cost categories: intervention, healthcare, patient and family, and productivity costs. More details on the measurement and valuation of the costs incorporated in the cost categories can be found in the Supplementary Data Table S1 (see Additional file 2).

\section{Statistical and economic analyses}

Baseline characteristics were compared for both groups by using analysis of variances (Anova), non-parametric Kruskal-Wallis analysis for continuous variables or Pearson's chi square test for categorical variables. We calculated the intra cluster correlation coefficients (ICC) of the RTW-SE, QUALY, health care costs and productivity costs. For the GWAS, we used an ANCOVA model with follow-up score as dependent variable and baseline score and study condition as independent variables to assess the effect of the intervention.

The differences in costs were calculated between both groups at the different measurement periods. Because cost distributions are often highly skewed, bootstrapping with 1000 replications was used to estimate bootstrap confidence intervals around the cost differences. Missing data were handled using SPSS missing value analysis on item level (mean imputation).

The differences in costs (incremental costs) were divided by the incremental effects, resulting in incremental cost effectiveness ratios (ICER). Non-parametric bootstrapping was also used to estimate the uncertainty surrounding the ICER (5000 replications). Afterwards, the bootstrapped cost effect pairs (i.e. ICERs) were plotted on the cost effectiveness planes.

Five sensitivity analyses were conducted to assess the robustness of the findings. First, 4 subgroup analyses were conducted to test for participant heterogeneity by assessing gender differences among patients and GPs. In the fifth sensitivity analysis changed working hours from baseline to 12 months follow-up served as the effect measure.

\section{Results}

\section{Baseline characteristics}

After 12 months follow-up, 280 patients were included in the economic evaluation: 131 in the intervention group and 149 in the control group (see Fig. 1).

The population characteristics are presented in Table 1. Most patients included in the study were female and permanently employed. The number of days absent from work in the past 6 months was higher in the intervention group but this difference was not statistically significant $(p=0.07)$. The average health care utilization costs were 


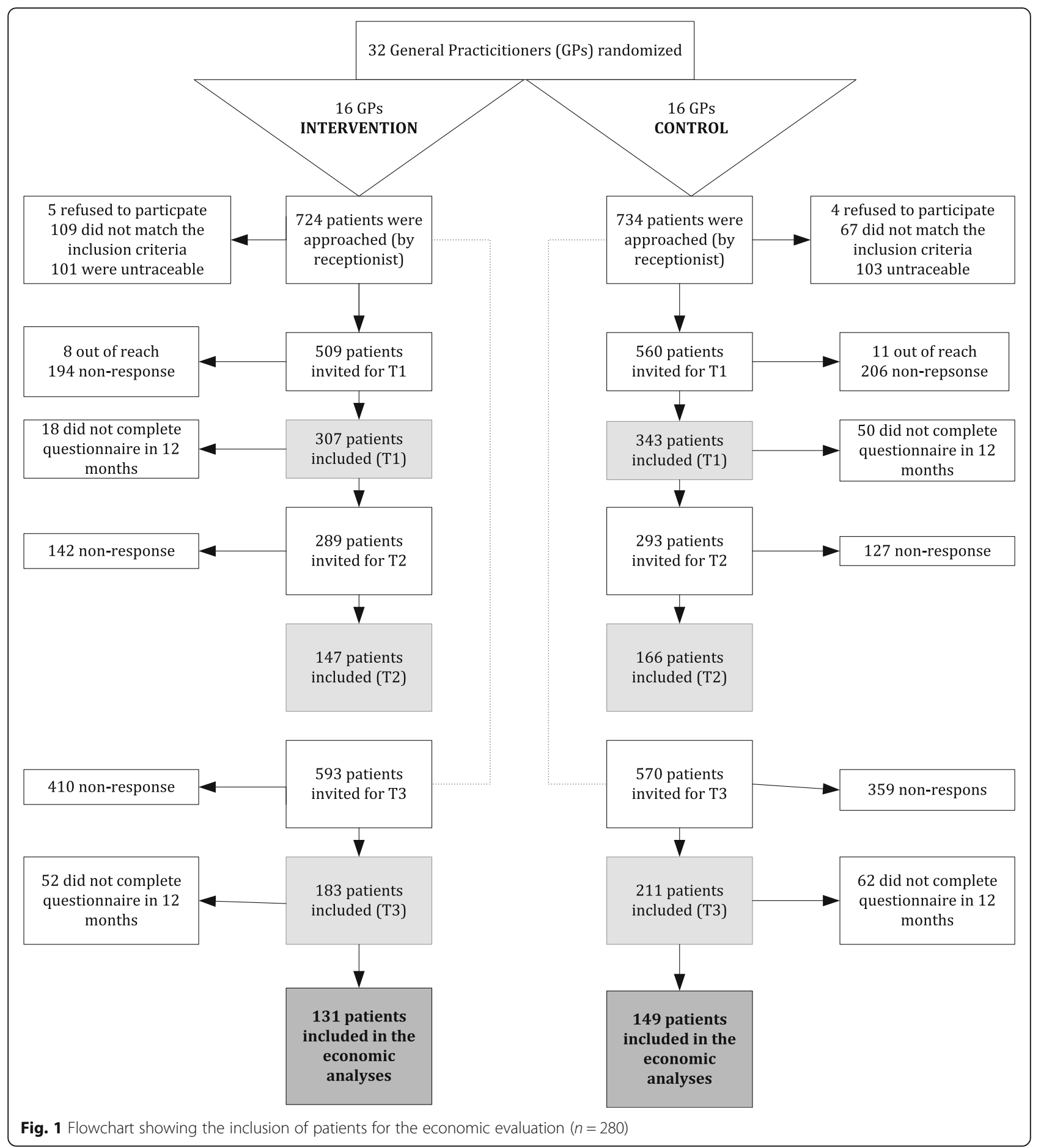

highest in the control group. All other cost categories were highest for the intervention group. At baseline, productivity costs accounted for the largest part of the total costs in both groups, with a significant difference in absenteeism costs between the groups. The ICC of the RTW-SE was 0.05 , the ICCs of Utility, health care costs and productivity costs were all $<0.001$.

\section{Outcome analysis}

The mean RTW-SE score at baseline was comparable and did not differ significantly $(p>0.05)$ between the intervention and the control group. Over time, scores on RTW-SE were comparable (at six-month follow-up control group 4.95 and intervention group 4.86; twelve months follow-up control group 4.9 and intervention group 4.92). 
Table 1 Baseline characteristics ( $N=280)$ (year of financial data = 2012)

\begin{tabular}{|c|c|c|c|}
\hline & Intervention $(n=131)$ & Control $(n=149)$ & $p$-value \\
\hline Age, mean (sd) & $45.14(10.01)$ & $46.41(10.96)$ & 0.31 (a) \\
\hline \multicolumn{4}{|l|}{ Gender, N (\%) } \\
\hline Female & $83(63)$ & $86(58)$ & \multirow[t]{2}{*}{$0.34(b)$} \\
\hline Male & $48(37)$ & $63(42)$ & \\
\hline \multicolumn{4}{|l|}{ Education, $N(\%) \dagger$} \\
\hline Low & $5(4)$ & $6(4)$ & \multirow[t]{3}{*}{0.67 (b) } \\
\hline Intermediate & $85(65)$ & $98(66)$ & \\
\hline High & $41(31)$ & $45(30)$ & \\
\hline Working hours, mean (sd) & $29.41(10.39)$ & $31.04(11.68)$ & $0.22(a)$ \\
\hline \multicolumn{4}{|l|}{ Job contract, $N(\%)$} \\
\hline Entrepreneur & $6(5)$ & $13(9)$ & \multirow[t]{7}{*}{$0.21(b)$} \\
\hline Employee (permanent employment) & $99(76)$ & $114(77)$ & \\
\hline Employee (temporary employment towards permanent employment) & $8(6)$ & $7(5)$ & \\
\hline Employee (temporary employment/fixed term) & $12(9)$ & $10(7)$ & \\
\hline Interim temporary worker & 1 & 1 & \\
\hline On call worker/substitute & 0 & $3(2)$ & \\
\hline Social Employment Law worker & $5(4)$ & 1 & \\
\hline \multicolumn{4}{|l|}{ Supervisor, $N(\%)$} \\
\hline One & $116(89)$ & $130(87)$ & \multirow[t]{2}{*}{$0.74(b)$} \\
\hline More than one & $15(11)$ & $19(13)$ & \\
\hline Managerial position, $N(\%)$ & $39(30)$ & $40(27)$ & 0.59 (b) \\
\hline Shift work, $N(\%)$ & $29(22)$ & $30(20)$ & $0.83(b)$ \\
\hline \multicolumn{4}{|l|}{ Job sector, $N(\%)$} \\
\hline Craft and industry & $15(11)$ & $25(17)$ & \multirow[t]{9}{*}{$0.46(b)$} \\
\hline Transport & $8(6)$ & $9(6)$ & \\
\hline Administration & $20(15)$ & $12(8)$ & \\
\hline Commercial & $14(11)$ & $22(15)$ & \\
\hline Services & $18(14)$ & $23(15)$ & \\
\hline Heath and care & $32(24)$ & $33(22)$ & \\
\hline Teaching & $11(8)$ & $7(5)$ & \\
\hline Specialist (discipline, expertise) & $10(7)$ & $15(10)$ & \\
\hline Agriculture & $3(2)$ & $3(2)$ & \\
\hline Self-rated general health ${ }^{*}$, mean (sd) & $72.69(21.5)$ & $75.6(21.3)$ & $0.26(a)$ \\
\hline Long term disability, N (\%) & $51(40)$ & $61(39)$ & $0.73(b)$ \\
\hline Days absent from work past 6 months, mean (sd) & $15.14(30.65)$ & $8.34(18.43)$ & 0.07 (a) \\
\hline EQ-5D-5 L Utilities, mean (sd) & $0.83(0.16)$ & $0.84(0.15)$ & $0.73(a)$ \\
\hline RTW-Self efficacy, mean (sd) & $4.74(1.29)$ & $4.77(1.15)$ & 0.83 (a) \\
\hline \multicolumn{4}{|l|}{ Costs, mean in $€(\mathrm{sd})$} \\
\hline Health care utilization & $452.74(647)$ & $562.28(2079)$ & $0.56(c)$ \\
\hline Medication and aids & $54.04(135)$ & $47.74(114)$ & 0.47 (c) \\
\hline Patient and family & $46.83(96.11)$ & $38.47(77.41)$ & $0.42(c)$ \\
\hline Informal care & $11.03(66.9)$ & $5.97(34.47)$ & $0.42(c)$ \\
\hline Travel and parking & $35.8(46.07)$ & $32.5(61.88)$ & $0.62(\mathrm{c})$ \\
\hline
\end{tabular}


Table 1 Baseline characteristics $(N=280)$ (year of financial data $=2012)$ (Continued)

\begin{tabular}{|c|c|c|c|}
\hline & Intervention $(n=131)$ & Control $(n=149)$ & $p$-value \\
\hline Productivity & $3906.58(10,878.11)$ & $2201.14(5208.97)$ & 0.09 (c) \\
\hline Absenteeism & $2426.83(5555.2)$ & $1245.96(3403.87)$ & $0.36(c)$ \\
\hline Presenteeism & 1479.75 (6312.95) & 955.18 (3205.42) & 0.37 (c) \\
\hline
\end{tabular}

Quality of life (utilities) at baseline was similar and did not differ significantly $(p>0.05)$ between the intervention and the control group. The change in quality of life after six-month follow-up (control group 0.86 and intervention group 0.86), and twelve months later (control group 0.86 and intervention group 0.87 ) was small. Quality of life was comparable for the intervention group (0.87; standard deviation (SD) 0.1 ) and the control group (0.86; SD 0.13), and did not differ significantly $(p=0.53)$.

The estimated marginal means of the GWAS for the intervention group GPs was 2.5 (95\% confidence interval (CI): 2.19-2.79) and for the control group GPs 2.1 (95\% CI: $1.82-2.44)(p=0.1)$.

\section{Cost analysis}

The intervention costs were almost negligible (€0.48). Healthcare costs for the 12-months follow-up were higher in the control group, both for health care utilization and medication usage. The mean cost difference of $€ 945$ was in favor of the intervention group. Also within the control group, more patient and family costs were made with a mean cost difference of $€ 82$ in favor of the intervention group. The productivity costs continued to account for the largest part of the mean total costs in both the control and intervention group. The difference in productivity costs between both groups $(€ 330)$ was in favor of the control group. In total, the bootstrapped total mean costs yielded an incremental difference of $€ 697$ in favor of the intervention group (Table 2).

\section{Incremental cost effectiveness ratio}

Based on the bootstrapped ICERs, no meaningful ICER for the cost effectiveness analysis was found. The ICERs are distributed almost equally among all the four quadrants of the plane (Fig. 2_a). The bootstrapped ICERs on the plane for the cost utility analysis (Fig. 2_b), presents similar results and demonstrates the harshness to correctly interpret the negative ICER $(-€ 87,214.28)$ because of the almost equal distribution of the cost effect pairs along the four quadrants.

No differences in RTW-SE between the intervention and control group were found (Table 3). A mean cost difference of $€ 770$ (95\% CI: $€-2936-€ 4351)$ was detected in favor of the intervention group.

Results of the sensitivity analyses are also shown in Table 3 . The 4 gender subgroups show no probability of the intervention becoming cost effective when studying RTW-SE among female or male patients, nor on the influence of female or male GPs on RTW-SE among their patients. However, based on the findings in the subgroup analyses, it could be suggested that if a positive effect of the intervention on RTW-SE could be found, female patients might be more sensitive to this effect in comparison to male patients. It might also be suggested that this is the case for female GPs; if patient's RTW-SE is attributable to the effort of GPs, female GPs might be more sensitive to achieve a positive effect on RTW-SE. The final sensitivity analysis, using work hours as an outcome measure, did not reveal other results.

\section{Discussion}

In this study we were able to analyse data of 280 patients recruited from the waiting room population of 16 intervention group GPs and 16 control group GPs. We found no effect of our intervention on the patients' work-related self efficacy or on their quality of life and no significant difference on societal costs or on the GPs' work awareness.

\section{Comparison with other studies}

The subject of work-related problems in general practice has been widely studied [15-20]. In most countries GPs have an important role in sickness certification. Our study was done among Dutch GPs who do not certify sickness. It corroborates the findings of the studies which used multifactorial analyses and concluded that GPs so far appear to have little influence on societal costs resulting from sickness absence.

Concerning the effect of training on GP behaviour we found several studies which demonstrated that training effectively changed GP behaviour, resulting in more patient-centered care and in patients being more satisfied [29, 30, 37]. Why have these studies been effective while ours was not effective? We consider extensive tailoring and continuous feedback as important elements for behaviour change in GPs [38]. These elements have been absent in our study. We expected our intervention 
Table 2 Total costs per cost category after 12 months follow-up $(N=280)$ (year of financial data $=2012)$

\begin{tabular}{|c|c|c|c|c|}
\hline Cost category & Intervention group $(*)$, costs $€$ & Control group(\#), costs $€$ & Incremental costs, $€$ & 2.5-97.5 percentile \\
\hline Intervention & 0.48 & 0 & & \\
\hline Health care utilization & 1130.98 & 2082.99 & & \\
\hline Medication and aids & 52.14 & 72.82 & & \\
\hline Bootstrapped subtotal, mean & 1177.74 & 2122.38 & -945 & $-2721-184$ \\
\hline \multicolumn{5}{|l|}{ Patient and family } \\
\hline Informal care & 34.04 & 94.2 & & \\
\hline Parking and travel & 52.62 & 73.41 & & \\
\hline Bootstrapped subtotal, mean & 86.39 & 168.37 & -82 & $-207-9$ \\
\hline \multicolumn{5}{|l|}{ Other sectors (productivity) } \\
\hline Absenteeism & 2675.22 & 2344.45 & & \\
\hline Presenteeism & 2214.72 & 2263.03 & & \\
\hline Bootstrapped subtotal, mean & 4936.95 & 4607.14 & 330 & $-2475-3113$ \\
\hline Bootstrapped total, mean & 6168.72 & 6865.56 & -697 & $-4351-2936$ \\
\hline
\end{tabular}

Note: Bootstrapped subtotal means might deviate due to rounding

${ }^{*}$ B Based on $\mathrm{n}=131$ (\#) Based on $\mathrm{n}=149$

to be beneficial for patients because of studies done in patients with mental health problems. Paying extra attention to work during their treatment, facilitated the return to work in patients with sickness absence because of common mental disorders and severe depression [39, 40]. It was also demonstrated that work-related self efficacy predicts return to work [34]. Therefore, we hypothesized that having GPs pay more attention to their patients' work, might result in an increase in their patients' work-related self efficacy, also in patients

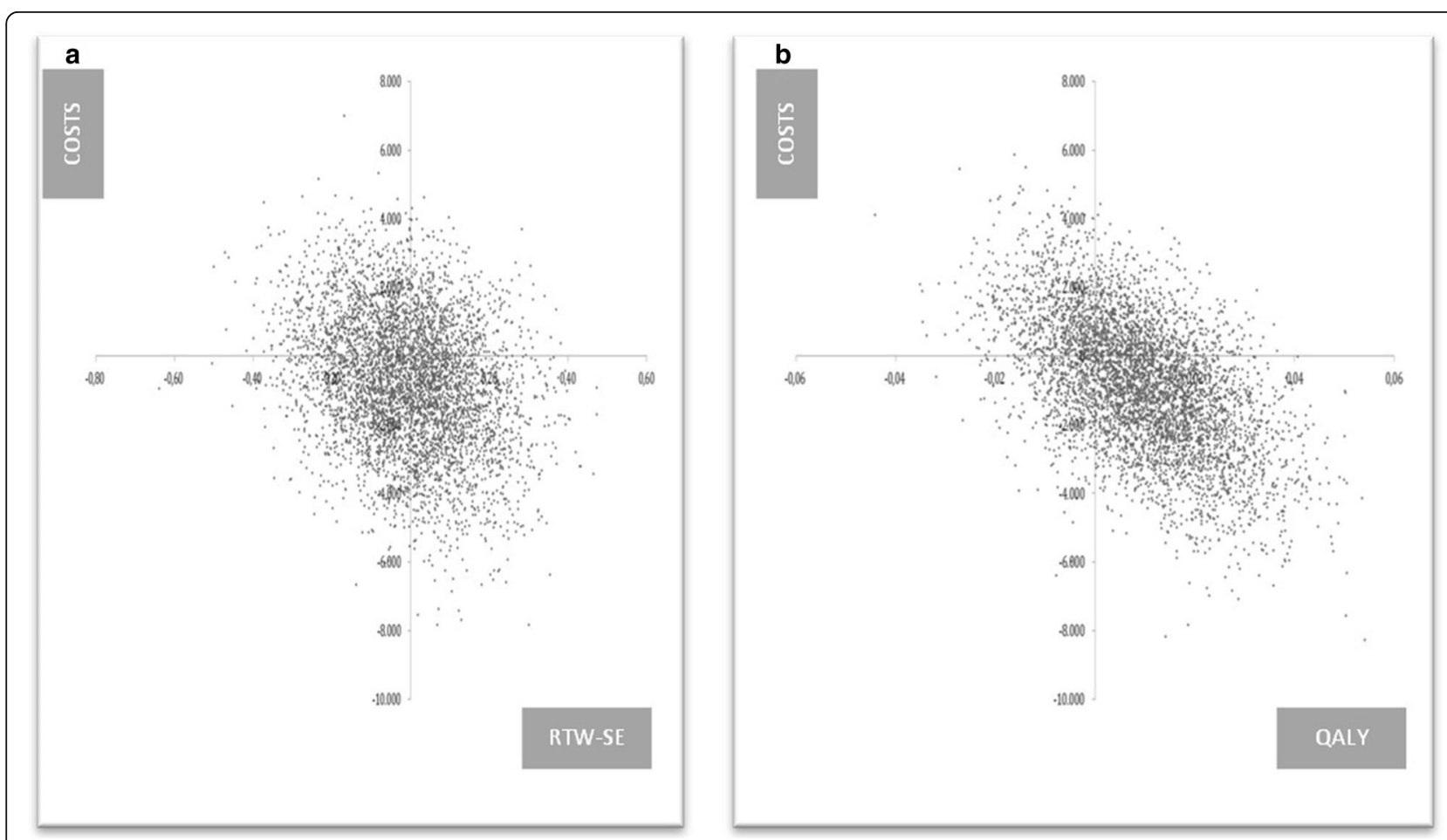

Fig. 2 Cost effectiveness planes illustrating (a) the cost effectiveness for work-related self efficacy (RTW-SE) among patients and (b) the costs utility for quality of life $(Q A L Y)(N=280$; financial data $=2012)$ a Cost effectiveness plane representing the uncertainty around the mean incremental costs and mean incremental effects (RTW-SE) of the intervention compared with the control condition. $\mathbf{b}$ Cost effectiveness plane representing the uncertainty around the mean incremental costs and mean incremental effects (QALY) of the intervention compared with the control condition 
Table 3 Mean cost and effect differences between the intervention and control group including incremental cost effectiveness and cost utility ratios, and cost effectiveness plane distributions

\begin{tabular}{|c|c|c|c|c|c|c|c|c|c|c|}
\hline & \multirow[t]{2}{*}{ Effect measure } & \multicolumn{2}{|c|}{ Sample Size } & \multirow[t]{2}{*}{$\Delta \operatorname{Cost}(€ 2012)$} & \multirow[t]{2}{*}{$\Delta$ Effect } & \multirow[t]{2}{*}{ ICER } & \multicolumn{4}{|c|}{ Distribution (\%) CEA plane (quadrant) } \\
\hline & & INT & CTR & & & & $\mathrm{NE}$ & SE (dominant) & SW & NW (inferior) \\
\hline \multicolumn{11}{|l|}{ Main analysis } \\
\hline Cost Effectiveness & RTW-SE & 131 & 149 & -770.67 & 0 & $168,376.09$ & 13 & 35 & 29 & 13 \\
\hline Cost Utility & QALY & 131 & 149 & -770.67 & 0.01 & $-87,214.28$ & 19 & 56 & 9 & 16 \\
\hline \multicolumn{11}{|c|}{ Subgroup \& Sensitivity analysis } \\
\hline Female GPs & RTW-SE & 46 & 57 & -2751.1 & 0.05 & $-50,730.37$ & 7 & 52 & 33 & 8 \\
\hline Male GPs & RTW-SE & 84 & 92 & 338.9 & -0.06 & -5745.96 & 16 & 21 & 23 & 40 \\
\hline Female patients & RTW-SE & 83 & 86 & -2914.6 & -0.03 & $111,755.92$ & 2 & 41 & 50 & 7 \\
\hline Male patients & RTW-SE & 48 & 63 & 2693.3 & 0.01 & $415,744.72$ & 38 & 14 & 6 & 42 \\
\hline Hours work & Working hours & 131 & 149 & -770.67 & 0.04 & $-17,655.77$ & 25 & 52 & 14 & 9 \\
\hline
\end{tabular}

INT = intervention group $\mid$ CTR = control group

$\mathrm{NE}=$ north-east quadrant of the cost effectiveness plane, which indicates the intervention is more effective and more costly than the control condition | SE = south-east quadrant of the cost effectiveness plane, which indicates the intervention is more effective and less costly than the control condition | SW = south-west quadrant of the cost effectiveness plane, which indicates the intervention is less effective and less costly than the control condition | NW = north-west quadrant of the cost effectiveness plane, which indicates the intervention is less effective and more costly than the control condition

with work-related problems who had continued working. That we did not find this in our study could be explained by the ceiling effect as, compared to other patients in which this instrument was used, the average RTW-SE score of the participating patients in our study was relatively high [34].

\section{Implications for future research}

For most workers, the GP practice is the point of access to the health care system but WRP can linger on for a long period of time without being recognised or addressed by GPs. Therefore, more effort should be put in strengthening the role of GPs with respect to the work of their patients. Future primary care-based studies should target subgroups of patients with an increased risk of WRP, e.g. patients with a chronic illness or mental health problem. In order to be successful, it is further recommended to use tailored implementation strategies providing both individualised and team level feedback [41]. In order to provide such feedback, outcome measures need to be selected and if needed developed, to align with expected effects of the intervention itself.

\section{Strengths and limitations}

This is the first RCT studying the cost effectiveness of training to increase the recognition and improve the management of WRP by GPs. Outcome measures were patients' work-related self-efficacy, quality of life and health care and productivity costs and GPs' work awareness. Other strengths of this study are the fact that it was conducted in routine daily clinical practice with data collected from workers recruited from the GP waiting room population, limiting potential selection bias of patients with absenteeism or WRP. Additional strengths are the successful randomization resulting in comparability of the intervention and control groups with respect to most characteristics, the inclusion of a broad measure for productivity costs [36] and the assessment of gender differences [42, 43]. Furthermore, the economic evaluation was carried out from a societal perspective.

Several limitations of our study need to be considered that may inform future studies: to start, we did not succeed in including a sufficient number of patients, meaning that we could not limit follow up to patients with WRP or chronic illness. This may have resulted in the ceiling effect, which made it difficult to detect an effect. A lack of tailoring of our intervention is another limitation. Offering individualised feedback and assistance in identifying and overcoming barriers might have helped the trained GPs to improve their performance. Another limitation that needs consideration is that the cost and effect data were obtained via patient self-reported retrospective questionnaires which may have caused recall bias, potentially over- or underestimating true healthcare utilization and healthcare costs. As there is no 'gold standard' for measuring healthcare utilization, the method used in this study provides at least crude estimates of actual usage [44]. Finally, the time span between the measurements occasionally reached over 12 months due to practical and logistical reasons, but the impact of potential recall bias was assumed to be equal for both groups due to the robust randomisation procedure.

\section{Conclusion}

Our training aimed at increasing GP work awareness and improving counselling for patients with WRP, did 
not result in an increased work-related self efficacy or quality of life among patients, nor did it significantly reduce societal costs or increase the work awareness among the GPs. It is expected that targeting at specific patient groups and tailoring of the intervention to individual GPs' needs will improve the intervention. Further, expected effects that align with the intervention content specifically should be tested.

\section{Additional files}

Additional file 1: "Questionnaire GPs@Work" Description: English language version of the questionnaire we have used in our study. (DOCX $115 \mathrm{~kb})$

Additional file 2: Supplementary Data Table S1. Description: Cost calculations per cost category (year of financial data =2012). (DOCX $24 \mathrm{~kb}$ )

Additional file 3: "Ethics waiver" Description: Letter from the institutional ethics review board concluding that approval was not needed according to Dutch law. (DOCX $11 \mathrm{~kb}$ )

\section{Abbreviations}

ANCOVA: Analysis of covariance; EQ-5D-5 L: EuroQoL 5 Dimensions 5 Levels; GP: General practitioner; GWAS: GP work awareness scale; ICC: Intra cluster correlation coefficients; ICER: Incremental cost effectiveness ratio; ICPC: International Classification of Primary Care; OP: Occupational physicians; QALY: Quality adjusted life years; RCT: Randomized controlled trial; RTWSE: Return To Work Self-Efficacy; WRP: Work-related problems

\section{Acknowledgements}

The authors wish to thank all participating GPs, practice receptionists and patients for making this study possible; Liesbeth Smits and Berend Terluin for their assistance with the design of the training intervention and their contributions during the intervention. They also wish to thank Margriet Straver, Lea Peters, Anouk Peters, Annetje Dieleman and Francine van den Driessen Mareeuw for their indispensable assistance with the data collection and Hugo de Waal for his help with the English language.

\section{Funding}

The study was funded by a research grant from the Foundation Institute Gak [grant number 2008-762].

\section{Availability of data and materials}

The datasets generated during and/or analyzed during the current study are not publicly available but are available from the corresponding author on reasonable request.

\section{Authors' contributions}

$C K, A L, A K, R S$ and PL conceptualised and designed the RCT. CK, AL and PL conducted the RCT and were involved in the acquisition of the data on the basis of which CN, AR, FN, RS and SE designed and performed the cost effectiveness analysis. CN and CK drafted the paper and all authors revised and commented on the first drafts of the paper and were actively involved in the revisions following the submission of the manuscript. Except for FN, who deceased in 2015, all authors have given final approval of the version to be published and take public responsibility for the content and agreed to be accountable for all aspects of the work and ensure that questions related to the accuracy or integrity of any part of the work are appropriately investigated and resolved.

\section{Ethics approval and consent to participate}

The institutional ethics review board concluded that approval was not needed according to Dutch Law (letter CMO 6th April 2011; see Additional file 3). Trial registration: The Netherlands Trial Register NTR3475 Registered 18 May 2012. Retrospectively registered. All patients and GPs who participated in our study were informed about the purpose of our study and gave their consent.
Consent for publication

Not applicable.

\section{Competing interests}

The authors declare that they have no competing interests.

\section{Publisher's Note}

Springer Nature remains neutral with regard to jurisdictional claims in published maps and institutional affiliations.

\section{Author details}

'Department of Primary and Community Care, Gender and Women's Health, Radboud University Nijmegen Medical Center, PO Box 9101, 6500, HB, Nijmegen, The Netherlands. ${ }^{2}$ Department of Health Services Research, CAPHRI School of Public Health and Primary Care, Maastricht University, Maastricht, The Netherlands. ${ }^{3}$ Department of Primary and Community Care, Radboud University Nijmegen Medical Center, Nijmegen, The Netherlands. ${ }^{4}$ Department of General Practice, Maastricht University, Maastricht, The Netherlands. ${ }^{5}$ Department of Social Medicine, CAPHRI School of Public Health and Primary Care, Maastricht University, Maastricht, The Netherlands. ${ }^{6}$ Department of Work and Social Psychology, Maastricht University, Maastricht, The Netherlands. ${ }^{7}$ TNO Work, Health and Care, Leiden, The Netherlands. ${ }^{8}$ Trimbos Institute, Netherlands Institute of Mental Health and Addiction, Utrecht, The Netherlands. ${ }^{9} \mathrm{OOR}$ ZON, Maastricht University Medical Centre, Maastricht, The Netherlands.

Received: 15 February 2018 Accepted: 18 February 2019

Published online: 02 March 2019

\section{References}

1. Hooftman WE, Mars GMJ, Janssen B, de Vroome EMM, van den Bossche SNJ Nationale enquête arbeidsomstandigheden 2014: methodologie en globale resultaten. [national survey on working conditions 2014: methodology and general results]. Leiden: TNO prevention, work and health; 2015. Dutch.

2. Weevers HJ, van der Beek AJ, Anema JR, van der Wal G, van Mechelen W. Work-related disease in general practice: a systematic review. Fam Pract. 2005;22(2):197-204.

3. van Dijk P, Hogervorst W, Buijs P, van Dijk F. Information in a Dutch GP registration system about high risks on long-lasting sickness absence: a cross sectional exploration in their registration system. Eur J Gen Pract. 2006;12(2):74-6.

4. Waddell G, Burton AK. Is work good for your health and well-being? London: The Stationnery Office; 2006. Available from: https://www.gov.uk/ government/uploads/system/uploads/attachment_data/file/214326/hwwbis-work-good-for-you.pdf.

5. Organisation for Economic Co-operation and Development. Sickness, Disability and Work: Breaking the Barriers. A Synthesis of Findings across OECD Countries. OECD. 2010. Available from: http://www.oecd.org/ publications/.

6. Wynne-Jones G, Mallen CD, Welsh V, Dunn KM. Rates of sickness certification in European primary care: a systematic review. Eur J Gen Pract. 2008;14(3-4):99-108.

7. Gezondheidsraad. Beoordelen, behandelen, begeleiden. Medisch handelen bij ziekteverzuim en arbeidsongeschiktheid [Health Council of the Netherlands. Assessment, treatment and counselling. Medical responses to sickness absenteeism en occupational disability]. Den Haag: Gezondheidsraad; 2005. Dutch.

8. Department of Work and Pensions: Getting the most out of the fit note. GP guidance. London: DWP; 2016.

9. Burton K, Kendall N, McCluskey S, Dibben P. Telephonic support to facilitate return to work: what works, how, and when? Research report 853. Department for Work and Pensions: Sheffield; 2013.

10. Cohen DA, Aylward M, Rollnick S. Inside the fitness for work consultation: a qualitative study. Occup Med (Lond). 2009;59(5):347-52.

11. Buijs P, van Amstel R, van Dijk F. Dutch occupational physicians and general practitioners wish to improve cooperation. Occup Environ Med. 1999;56(10):709-13.

12. Buijs PC, Weel AN, Nauta NP, Anema HR, Schoonheim PL, Helsloot RS. Teaching general practitioners and occupational physicians to cooperate: joint training to provide better care for European workers. The Eur J Gen Pract. 2009;15(3):125-7. 
13. Nauta AP. Een vertrouwenskwestie? Over het samenwerken van huisartsen en bedrijfsartsen [A matter of trust? About the collaboration between general practitioners and occupational physicians. Dissertation]. Heerlen: Open Universiteit 2004 Dutch.

14. Bakker RH. De samenwerking tussen huisarts en bedrijfsarts [the cooperation between general practitioner and occupational physician. Dissertation]. Groningen: Rijksuniversiteit Groningen 2005. Dutch.

15. Agius RM, Hussey LJ. Certified sickness absence: does the 'fit-note' work? Occup Environ Med. 2015;72(7):463-4.

16. Faber E, Bierma-Zeinstra SM, Burdorf A, Nauta AP, Hulshof CT, Overzier PM et al. In a controlled trial training general practitioners and occupational physicians to collaborate did not influence sickleave of patients with low back pain. J Clin Epidemiol. 2005;58(1):75-82.

17. Shiels C, Gabbay MB, Ford FM. Patient factors associated with duration of certified sickness absence and transition to long-term incapacity. $\mathrm{Br} J$ Gen Pract. 2004;54(499):86-91

18. Winde LD, Hansen HT, Gjesdal S. General practitioner characteristics and sickness absence--a register-based study of 348054 employed Norwegians. Eur J Gen Pract. 2011;17(4):210-6.

19. Gabbay M, Shiels C, Hillage J. Factors associated with the length of fit note-certified sickness episodes in the UK. Occup Environ Med. 2015;72(7):467-75

20. Rudbeck M. Variation in patients' sick leave between general practitioner practices. Scand J Public Health. 2014;42(7):621-6.

21. Wynne-Jones G, Mallen CD, Main CJ, Dunn KM. What do GPs feel about sickness certification? A systematic search and narrative review. Scand J Prim Health Care. 2010;28(2):67-75.

22. Halvorsen PA, Edwards A, Aaraas IJ, Aasland OG, Kristiansen IS. What professional activities do general practitioners find most meaningful? Cross sectional survey of Norwegian general practitioners BMC Fam Pract. 2013;14:41.

23. Letrilliart $L$, Barrau A. Difficulties with the sickness certification process in general practice and possible solutions: a systematic review. Eur J Gen Pract. 2012;18(4):219-28.

24. Higgins A, Porter S, O'Halloran P. General practitioners' management of the long-term sick role. Soc Sci Med. 2014;107:52-60.

25. Buijs P, Tudor HJ. Why Dutch GPs do not certify. Br J Gen Pract. 1997;12: 860-1.

26. CoFPo C. A vision for Canada: family practice-the Patient's medical home. College of Family Physicians of Canada: Mississauga, ON; 2011.

27. NHG-standpunt kernwaarden huisartsengeneeskunde. Generalistisch, persoonsgericht en continu [Dutch College of General Practitioners. Position paper on core values of general practice. Generalist, person centered and continuous] Utrecht: NHG; 2011. Dutch.

28. Frank J, Snell L, Sherbino J. The CanMEDS 2015 physician competency framework. The Royal College of Physicians and Surgeons of Canada: Ottawa; 2015.

29. Hobma S, Ram P, Muijtjens A, van der Vleuten C, Grol R. Effective improvement of doctor-patient communication: a randomised controlled trial. Br J Gen Pract. 2006;56(529):580-6.

30. Wong SLF, Wester F, Mol SS, Lagro-Janssen TL. Increased awareness of intimate partner abuse after training: a randomised controlled trial. Br J Gen Pract. 2006;56(525):249-57.

31. De Kock KA, Steenbeek R, Buijs PC, Lucassen PL, Knottnerus JA, LagroJanssen AL. An education programme to increase general practitioners' awareness of their patients' employment: design of a cluster randomised controlled trial. BMC Fam Pract. 2014;15:28.

32. De Kock CA, Lucassen PL, Bor H, Knottnerus JA, Buiis PC, Steenbeek R, Lagro Janssen ALM. Training GPS to improve their management of work-related problems: results of a cluster randomized controlled trial. Eur J Gen Pract. 2018:24:258-65.

33. De Kock CA, Lucassen PL, Spinnewijn L, Knottnerus JA, Buijs PC, Steenbeek $R$, et al. How do Dutch GPs address work-related problems? A focus group study. Eur J Gen Pract. 2016;22:169-75.

34. Lagerveld SE, Blonk RW, Brenninkmeijer V, Schaufeli WB. Return to work among employees with mental health problems: development and validation of a self-efficacy questionnaire. Work Stress. 2010;24:359-75.

35. EuroQol. EQ-5D-5L Value Sets [cited 2014]. Available from: https://euroquol. org/eq-5d-instruments/eq-5d-5l-about/valuation-standard-value-sets/.

36. Krol M, Papenburg J, Koopmanschap M, Brouwer W. Do productivity costs matter? The impact of including productivity costs on the incremental costs of interventions targeted at depressive disorders. Pharmacoeconomics. 2011;29(7):601-19.

37. Sinnema $H$, Terluin $B$, Wensing $M$, Volker D, Franx $G$, van Balkom A, et al. Systematic tailoring for the implementation of guideline recommendations for anxiety and depressive disorders in general practice: perceived usefulness of tailored interventions. BMC Fam Pract. 2013;14:94.

38. Dwamena F, Holmes-Rovner M, Gaulden CM, Jorgenson S, Sadigh G, Sikorskii A, et al. Interventions for providers to promote a patient-centred approach in clinical consultations. Cochrane Database Syst Rev. 2012;12:No.: CD003267.

39. Lagerveld SE, Blonk RW, Brenninkmeijer V, Wijngaards-de Meij L, Schaufeli WB. Work-focused treatment of common mental disorders and return to work: a comparative outcome study. J Occup Health Psychol. 2012;17(2):220-34

40. Hees HL, de Vries G, Koeter MW, Schene AH. Adjuvant occupational therapy improves long-term depression recovery and return-to-work in good health in sick-listed employees with major depression: results of a randomised controlled trial. Occup Environ Med. 2013;70(4):252-60.

41. Noben C, Evers S, van Genabeek J, Nijhuis F, de Rijk A. Improving a webbased employability intervention for work-disabled employees: results of a pilot economic evaluation. Disabil Rehabil Assist Technol 2017. 2017:12(3):280-9.

42. Shiels C, Gabbay M. The influence of GP and patient gender interaction on the duration of certified sickness absence. Fam Pract. 2006;23(2):246-52.

43. Lagro-Janssen AL. De geneeskunde is niet genderneutraal: invloed van de sekse van de dokter op de medische zorg. [Medicine is not gender-neutral: influence of physician sex on medical care] Ned Tijdschr Geneeskd 2008(152):141-5. Dutch.

44. Noben C, de Rijk A, Nijhuis F, Kottner J, Evers S. The exchangeability of self-reports and administrative health care resource use measurements: assessement of the methodological reporting quality. J Clin Epidemiol. 2016;74:93-106
Ready to submit your research? Choose BMC and benefit from:

- fast, convenient online submission

- thorough peer review by experienced researchers in your field

- rapid publication on acceptance

- support for research data, including large and complex data types

- gold Open Access which fosters wider collaboration and increased citations

- maximum visibility for your research: over $100 \mathrm{M}$ website views per year

At BMC, research is always in progress.

Learn more biomedcentral.com/submissions 